Open Access

\title{
Prolonged Hypothermia (over 6 months) in a 10-month-old Infant, Case Report and Review of Temperature Regulation and Hypothermia
}

\author{
Giraudo $\mathrm{F}^{1}$, Sofía Aros $^{2}$, Gilbert Handal ${ }^{3 *}$ and Barrera $\mathrm{F}^{2}$ \\ ${ }^{1}$ Ph.D Student, Medical Sciences and Pediatrics, University of Chile, Chile \\ ${ }^{2}$ Pediatrician, Pediatrics Service, San Borja Arriarán Clinical Hospital, Chile \\ ${ }^{3}$ Professor, Department of Pediatrics, Texas Tech University Health Sciences Center at El Paso, El Paso, Texas, USA
}

\section{Article Info}

\author{
*Corresponding author: \\ Gilbert Handal \\ Professor \\ Department of Pediatrics \\ Texas Tech University Health Sciences \\ Center \\ Texas, USA \\ E-mail: Gilbert.Handal@ttuhsc.edu
}

Received: March 14, 2019

Accepted: April 8, 2019

Published: April 15, 2019

Citation: Giraudo F, Aros S, Handal G, Barrera F. Prolonged Hypothermia (over 6 months) in a 10-month-old Infant, Case Report and Review of Temperature Regulation and Hypothermia. Int J Pediatr Neonatal Prim Care. 2019; 1(1): 17-20.

doi: 10.18689/ijpn-1000105

Copyright: @ 2019 The Author(s). This work is licensed under a Creative Commons Attribution 4.0 International License, which permits unrestricted use, distribution, and reproduction in any medium, provided the original work is properly cited.

Published by Madridge Publishers

\begin{abstract}
Case of a 10-month-old infant girl with prolonged hypothermia (over 6 months) following two viral infections with negative work-up for other etiology of the persistent hypothermia.
\end{abstract}

Keywords: Infant; Hypothermia; Temperature Regulation.

\section{Introduction}

Case report of a 10-month-old infant girl with prolonged hypothermia that occurred after having viral laryngitis at 9 months of age, enterocolitis from Clostridium Difficile (treated with Diclofenac) at 10 months of age, and type 3 para influenza virus. The hypothermia started one day after Diclofenac was given to treat Clostridium Difficile. Further, this paper also includes a review of temperature regulation and hypothermia in humans.

\section{H\&P}

Healthy 10 -month-old girl born by spontaneous vaginal delivery with a birth weight of 3,990 g, length $49 \mathrm{~cm}$, and head circumference $35 \mathrm{~cm}$, her parents were healthy, the infant girl was exclusively breastfed. Her perinatal screening was negative.

At 9 months of age the infant had laryngitis treated with Betamethasone $0.15 \mathrm{mg} /$ $\mathrm{kg} / \mathrm{d}$ for 3 days. A month after the treatment, she was presented with enterocolitis and respiratory distress and was diagnosed with Para influenza type 3 and Clostridium Difficile, bot by PCR. The child received a single dose of Diclofenac, $12.5 \mathrm{mg}$ IM. The day after the infant started with symptomatic hypothermia of $35^{\circ} \mathrm{C}\left(95^{\circ} \mathrm{F}\right)$ axillary, which presented daily for the next two weeks, between 22:30 and 01:00 (Figure 1).

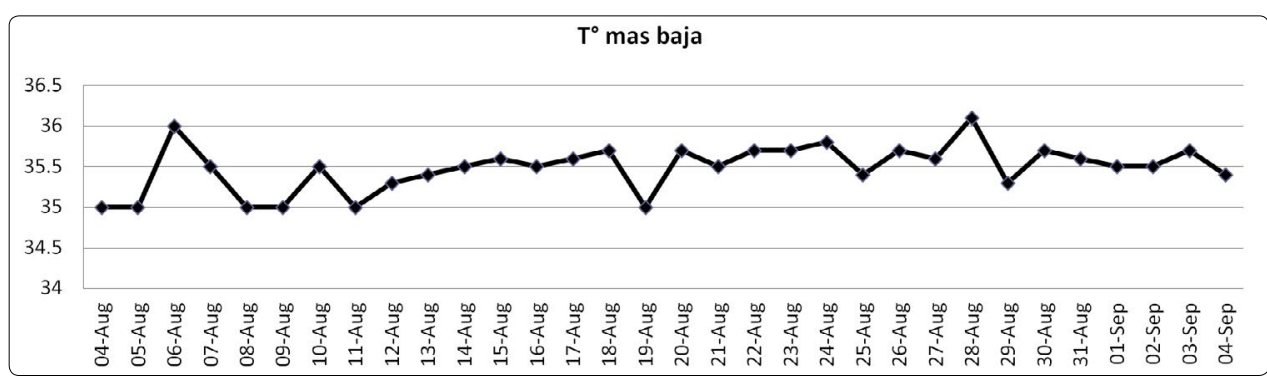

Figure 1. Daily axillary temperatures between August 4 and September 4, 2017 
Symptoms included cold face, lower legs and feet and generalized cold sweating. For the next two months she had occasional nocturnal hypothermia episodes and the symptoms decreased but requiring, nevertheless, special warming precautions that included room temperature at $24^{\circ} \mathrm{C}\left(75.2^{\circ} \mathrm{F}\right)$ and wrapping the infant girl in absorbent paper towels and cotton blankets that were changed frequently as they became moist with her sweat, she was also covered with sheepskin on top of the cotton blankets.

The differential diagnosis considered a hypothalamic or encephalitic component either as a consequence of the primary infection or secondary to a host immune reaction to the infection, although the patient never presented any signs of encephalic compromise, the possibility of a metabolic condition and the very unlikely possibility of Shapiro Syndrome variants.

At 13 months, after consultation with Dr. Paul A. Offit, Director of Vaccine at the Children Hospital of Philadelphia and Dr. CHOP and the CDC Consultant in the Immunization Section of the Centers for Disease Control and Prevention (CDC) the child received all age-appropriate immunizations, which she tolerated without complications.

Three days after the immunizations she had mild hypothermia of $35.6^{\circ} \mathrm{C}$ with minimal symptoms. Over the next three months the child slept with her mother who used extra warming measures as described above. The child's temperature increased by about 0.1 degrees Celsius $\left(0.18^{\circ} \mathrm{F}\right)$ each month for the next three months. At her last pediatric follow-up, at 19 months of age, her axillary temperature was $35.6^{\circ} \mathrm{C}\left(96.08^{\circ} \mathrm{F}\right)$ at night and she was asymptomatic. Her psychological development and Weight, Height and $\mathrm{HC}$ were appropriate and normal.

The family history is remarkable for a 6 year old cousin who gets occasional hypothermia, particularly when she takes acetaminophen and a 17 year old cousin who has a normal body temperature of 35.8. Both are asymptomatic.

\section{Diagnostic Focus and Assessment}

The work-up included also, CBC, CMP, thyroid studies, cortisol levels morning and evening, progesterone levels, and frequent blood sugar monitoring. An MRI was also obtained and the entire work up was normal. Repeated viral studies were negative.

The management of the child was only symptomatic with particular attention to warming and cleaning the cold sweat particularly present in the face of the child the room temperature was kept at $24^{\circ} \mathrm{C}\left(75.2^{\circ} \mathrm{F}\right)$, was wrapped on absorbent paper towels, which were changed frequently, double blankets and a sheepskin, this was typically between 22:30 and 01:00 hours.

\section{Discussion}

\section{Temperature regulation}

In mammals temperature fluctuates following circadian rhythms. Many factors such as aging, menstruation or some diseases may decrease (hypothermia) or increase (hyperthermia) the body's temperature [1]. To maintain the body temperature stable, the production of heat must be equal to the heat loss through evaporation, radiation, conduction, and convection [2]. The pre-optic area of the hypothalamus seems to be the most important organ involved in the body's autonomic regulation [2].

The awake-sleep cycle and temperature are affected by environmental stimuli [3]. There seems to be a close correlation between sleepiness and decrease body's central temperature but this link is controversial. In humans the regulation of body temperature starts by 6 weeks of age and it achieves full regulation by 10 weeks of age [4]. Further, research has shown that melatonin decreases central temperature between 0.3 and 0.4 degrees Celsius $\left(0.54\right.$ and $\left.0.72^{\circ} \mathrm{F}\right)$, except in older individuals and women during the luteal phase [5].

In infants, studies have suggested that rectal temperature decreases during sleep, perhaps due to a redistribution of the blood flow more so than an increase or decrease of heat production [6]. This pattern occur between the $7^{\text {th }}$ and $17^{\text {th }}$ week of life with the lowest temperature recorded at $36.4^{\circ} \mathrm{C}$ $\left(97.52^{\circ} \mathrm{F}\right)$, however, this may differ until the adult pattern of stable temperature is reached [7]. Exclusively breastfed infants, female infants, first-born infants, and infants born to older mothers typically reach a stable body temperature faster [8]. In contrast, rapid weight gain delays reaching a stable body temperature. Sleep position in infants, as a factor to reach a stable temperature faster, has not been evaluated [9].

\section{Temperature measurement}

In humans body temperature in ambulatory settings is measured in the axillae, mouth, temporal artery, or tympanic in ambulatory settings. Axillary temperature correlates well with central temperature in the newborn only. Nevertheless, axillary temperature measurement is very reliable if taken by the same individual and following the recommended technique. To take the most accurate axillary temperature the thermometer needs to be in the center of dry axillae, the thermometer needs to be covered completely with the arm, and the thermometer needs to be kept on the axillae for three to five minutes, until the reading stabilizes. Nowadays, the most reliable ambulatory thermometer is the infrared Otic device (the measurements are even more accurate if the Otic thermometer uses an electronic thermistor) [10].

\section{Hypothermia}

Hypothermia, or low body temperature of less than $35^{\circ} \mathrm{C}$ $\left(95^{\circ} \mathrm{F}\right)$ [1] or less than $36^{\circ} \mathrm{C}\left(96.8^{\circ} \mathrm{F}\right)$ and symptomatic. These include: sweating (occasionally), chills, tremors, pallor, lethargy, and cold face and cold lower legs and feet, when persistent can lead to a decreased metabolism and freezing and crystallization of electrolytes and enzymes that can reach toxic levels. Also leads to dehydration and reflex vasoconstriction to retain heat, which causes tissue infarct and necrosis. The basal metabolism in the body increases 6 times at $35^{\circ} \mathrm{C}\left(95^{\circ} \mathrm{F}\right)$, however, this compensatory response 
decreases to only $50 \%$ at $28^{\circ} \mathrm{C}\left(82.4^{\circ} \mathrm{F}\right)$. We can assess hypothermia using as a mortality index, but also we can look at hypothermia as a condition that is slowly evolving and with appropriate treatment it can improve.

The most frequent cause of Hypothermia is due to environmental exposure and from these; the best documented cases are in high mountain climbers. It can be classified as mild when the body temperature is between $32^{\circ} \mathrm{C}$ and $35^{\circ} \mathrm{C}$ $\left(89.6^{\circ} \mathrm{F}-95^{\circ} \mathrm{F}\right)$, moderate with a body temperature between $27^{\circ} \mathrm{C}$ and $32^{\circ} \mathrm{C}\left(80.6^{\circ} \mathrm{F}-89.6^{\circ} \mathrm{F}\right)$ and severe when body temperature is lower than $27^{\circ} \mathrm{C}\left(80.6^{\circ} \mathrm{F}\right)$. According to its evolution hypothermia can be classified as acute, sub-acute, or chronic. Acute hypothermia has no metabolic or physiologic side effects and usually occurs as a result of an accident. Subacute hypothermia is mild and mostly reversible and often occurs because the individual is not protected against the cold. Chronic hypothermia, however, presents usually in infants and children or older individuals and it relates to comorbidities and other conditions [11]. Chronic hypothermia is frequently associated with severe symptoms such as decreased heart and respiratory rate, shivering, altered mental processing, midriasis, hypotension and muscle dysfunction. In chronic hypothermia at $32^{\circ} \mathrm{C}\left(89.6^{\circ} \mathrm{F}\right)$ the individual presents in a coma with absent reflexes. If body temperature drops below $27^{\circ} \mathrm{C}\left(80.6^{\circ} \mathrm{F}\right)$ the respiratory, hematologic, and neuromuscular changes are lethal. At $15^{\circ} \mathrm{C}\left(59^{\circ} \mathrm{F}\right)$ there is arrhythmias followed by cardio respiratory arrest.

In the newborn and infants hypothermia usually reflects an immature thermoregulation mechanism and it is associated to accidental extreme cold exposure [12].

A systematic review [13] of causes of hypothermia divides the etiology into:

- Cutaneous disorders: such as burns, exfoliative dermatitis, severe psoriasis

- Drug induced: alcohol, phenothiazine's, sedating medications and hypnotics

- Environmental: secondary to immersion or nonimmersion

- latrogenic: vigorous resuscitation, heat treatment

- Metabolic: decreased adrenal, pituitary or thyroid function

- Neurologic: spinal transection, acute brain traumatic injury, tumors and Wernicke's syndrome

- Neuromuscular disorders: extreme ages, inability to make environmental changes

- Sepsis

- Others: mitochondrial disorders

The incidence of the classic Shapiro Syndrome, with agenesis of the Corpus Callosum with classic symptoms of hyperhidrosis and hypothermia is extremely infrequent as there are less than 50 cases documented, this disorder is characterized by episodic hypothermia [14,15], the pharmacological treatment is ineffective and the increased risk on their siblings suggest an autosomal recessive inheritance [12]. As stated is more frequent in adults but some variants may present in older children.

Ruiz et al. described 4 older children, between the ages of 4 and 9 years old, with similar signs and symptoms in the absence of brain damage. The body temperature in these children was between $33^{\circ} \mathrm{C}$ and $35^{\circ} \mathrm{C}\left(91.4-95^{\circ} \mathrm{F}\right)$ and it was associated with migraines, pallor, and absent chills. Some had hypertension, abdominal pain, and cold sweats. They also had a normal neurologic examination and brain MRI, but their CSF showed low levels of serotonin and dopamine [16,17] eventually all of these 4 children stopped having hypothermia.

There is one single report of a patient with hypothermia associated with infection by Respiratory Syncytial Virus (RSV). The authors of this article mention that there could be central hypothalamic alteration due to hyper sensibility [18].

Hypothermia can reduce the inflammatory process and, in some birds, this mechanism is important as a defense mechanism to combat infections, sometimes alternating episodes of hyperthermia and hypothermia. These could be modulated by the intrinsic flora and had been demonstrated in models of alterations of the micro biome associated with the use of antibiotics [1]. In the treatment of the septic patient, hypothermia has also been used as a mechanism of decrease metabolism, heart and respiratory rates and oxygen consumption [1].

The recommended treatment of hypothermia include warming, hydration including sometimes warmed solutions, cardiovascular support, and close monitoring as deaths associated with hypothermia are twice as frequent as deaths associated with hyperthermia [10].

\section{Conclusion}

This case reports persistent hypothermia in an infant associated with an acute viral infection that received one dose of diclofenac. A review of the literature demonstrated only one other similar case associated with a child who had RSV infection. We felt it was important to report this case as it can help other physicians as it demonstrates the correlation between a viral illness and persistent hypothermia and the conservative management advised in their care. It is important also to assess the child in a short time and the home care preferable with parents that will provide the appropriate management as they understand the process.

\section{References}

1. Schieber AM, Ayres JS. Thermoregulation as a disease tolerance defense strategy. Pathog Dis. 2016; 74(9). doi: 10.1093/femspd/ftw106

2. Tansey EA, Johnson CD. Recent advances in thermoregulation. Adv Physiol Educ. 2015; 39(3): 139-148. doi: 10.1152/advan.00126.2014

3. Gilbert SS, van den Heuvel CJ, Ferguson SA, Dawson D. Thermoregulation as a sleep signalling system. Sleep Med Rev. 2004; 8(2): 81-93. doi: 10.1016/ S1087-0792(03)00023-6

4. Guilleminault C, Leger D, Pelayo R, Gould S, Hayes B, Miles L. Development of circadian rhythmicity of temperature in full-term normal infants. Neurophysiol Clin. 1996; 26(1): 21-29. doi: 10.1016/0987-7053(96)81531-0 
5. Cagnacci A, Krauchi K, Wirz-Justice A, Volpe A. Homeostatic versus circadian effects of melatonin on core body temperature in humans. J Biol Rhythms. 1997; 12(6): 509-517. doi: 10.1177/074873049701200604

6. Tappin DM, Ford RP, Price B, Macey PM, Larkin J. Overnight central and peripheral temperature changes in normal infants. Acta Paediatr. 2003; 92(9): 1003-1006.

7. Petersen SA, Pratt C, Wailoo MP. Relations between the development of patterns of sleeping heart rate and body temperature in infants. Arch Dis Child Fetal Neonatal Ed. 2001; 85(2): F133-F136. doi: 10.1136/fn.85.2.F133

8. Lodemore MR, Petersen SA, Wailoo MP. Factors affecting the development of night time temperature rhythms. Arch Dis Child. 1992; 67(10): 12591261.

9. Grover G, Berkowitz CD, Lewis RJ, Thompson M, Berry L, Seidel J. The effects of bundling on infant temperature. Pediatrics. 1994; 94(5): 669673.

10. Cheshire WP Jr. Thermoregulatory disorders and illness related to heat and cold stress. Auton Neurosci. 2016; 196: 91-104. doi: 10.1016/j. autneu.2016.01.001

11. Martyn JW. Diagnosing and treating hypothermia. Can Med Assoc J. 1981; 125(10): 1089-1096.
12. Tambasco N, Belcastro V, Prontera $P$, et al. Shapiro's syndrome: Defining the clinical spectrum of the spontaneous paroxysmal hypothermia syndrome. Eur J Paediatr Neurol. 2014; 18(4): 453-457. doi: 10.1016/j. ejpn.2014.02.001

13. McCullough $\mathrm{L}$, Arora S. Diagnosis and treatment of hypothermia. Am Fam Physician. 2004; 70(12): 2325-2332.

14. Klingler ET, Meyer K. Shapiro's syndrome: a renewed appreciation for vital signs. Clin Infect Dis. 2004; 38(10): e107-e108. doi: 10.1086/386337

15. Shapiro WR, Williams GH, Plum F. Spontaneous recurrent hypothermia accompanying agenesis of the corpus callosum. Brain. 1969; 92(2): 423436.

16. Ruiz C, Gener B, Garaizar C, Prats JM. Episodic spontaneous hypothermia: a periodic childhood syndrome. Pediatr Neurol. 2003; 28(4): 304-306.

17. Rodrigues Masruha M, Lin J, Arita JH, et al. Spontaneous periodic hypothermia and hyperhidrosis: a possibly novel cerebral neurotransmitter disorder. Dev Med Child Neurol. 2011; 53(4): 378-380. doi: 10.1111/j.1469-8749.2010.03854.x

18. Milner D, Wailoo MP, Swift PGF, Fraser M. Prolonged hypothermia following respiratory syncytial viral infection in infancy. Arch Dis Child 2003; 88(1): 69-70. doi: 10.1136/adc.88.1.69 